\title{
Does evidence really matter? Professionals' opinions on the practice of early mobilization after stroke
}

This article was published in the following Dove Press journal:

Journal of Multidisciplinary Healthcare

2I October 20II

Number of times this article has been viewed

\author{
Anna Sjöholm ${ }^{1,2}$ \\ Monica Skarin ${ }^{1,2}$ \\ Thomas Linden ${ }^{1,2}$ \\ Julie Bernhardt ${ }^{2}$ \\ 'Department of Clinical Neuroscience \\ and Rehabilitation, Institute of \\ Neuroscience and Physiology, \\ The Sahlgrenska Academy at \\ Gothenburg University, Gothenburg, \\ Sweden; ${ }^{2}$ Stroke Division, Florey \\ Neuroscience Institutes, La Trobe \\ University, Melbourne, Australia
}

Introduction: Early mobilization after stroke may be important for a good outcome and it is currently recommended in a range of international guidelines. The evidence base, however, is limited and clear definitions of what constitutes early mobilization are lacking.

Aims: To explore stroke care professionals' opinions about (1) when after stroke, first mobilization should take place, (2) whether early mobilization may affect patients' final outcome, and (3) what level of evidence they require to be convinced that early mobilization is beneficial.

Methods: A nine-item questionnaire was used to interview stroke care professionals during a conference in Sydney, Australia.

Results: Among 202 professionals interviewed, $40 \%$ were in favor of mobilizing both ischemic and hemorrhagic stroke patients within 24 hours of stroke onset. There was no clear agreement about the optimal time point beyond 24 hours. Most professionals thought that patients' final motor outcome (76\%), cognitive outcome (57\%), and risk of depression (75\%) depends on being mobilized early. Only $19 \%$ required a large randomized controlled trial or a systematic review to be convinced of benefit.

Conclusion: The spread in opinion reflects the absence of clear guidelines and knowledge in this important area of stroke recovery and rehabilitation, which suggests further research is required.

Keywords: stroke, rehabilitation, early ambulation, early mobilization observation

\section{Introduction}

Stroke unit care is proven to increase the chance of survival and physical independence after stroke. ${ }^{1}$ However, it is not yet clearly understood what particular components of stroke unit care are responsible for these benefits. ${ }^{2}$ One factor that may play an important role is early mobilization, which is characterized by getting patients out of bed within 24 hours of stroke and continuing frequent out of bed activity throughout their stay. ${ }^{3}$

It has been reported that mobilization in this early phase of stroke appears to be safe, ${ }^{4}$ may help to minimize immobility-associated complications, ${ }^{3,5-9}$ and have significant psychological effects. ${ }^{3,10}$ However, some researchers hold the opinion that lying flat for the first 24-72 hours is important to maintain cerebral blood flow to the ischemic tissue, which may still be viable if blood flow is restored (the penumbra). ${ }^{11}$ Two small pilot randomized controlled trials have directly studied early mobilization after stroke ${ }^{4,9}$ and a large international randomized controlled trial is currently underway. ${ }^{12}$ A proposed protocol of 3 days rest prior to commencing mobilization has yet to be tested. ${ }^{11}$ This highlights that there are strongly held views in both directions.
Correspondence: Julie Bernhardt Stroke Division, Florey Neuroscience Institutes, Melbourne Brain Centre, 245 Burgundy Street, Heidelberg, Victoria 3084, Australia

Tel +6I 394962783

Fax +61394962650

Email j.bernhardt@unimelb.edu.au 
Early mobilization is nevertheless recommended in a range of international guidelines ${ }^{13-17}$ but what is meant by "early" or "mobilization" is not well described. In the literature, some define "mobilization" as any physical activity, independent of body position (flat, sitting, or upright), and whether it is the patient or the environment initiating the movement of the body. ${ }^{11}$ Others denote that the term, in this context, should only be used for out of bed activity, since activity performed in bed gives very little opportunity for movement and therefore ought to be called bed rest. ${ }^{18}$ "Early" is also defined in various ways. For instance, as meaning within 24 hours, ${ }^{3}$ within the first 3 days, ${ }^{11}$ and within the first week after stroke onset. ${ }^{19}$

It is therefore likely that current practices are based on historical precedent and professional opinion, resulting in a variety of approaches to mobilization. ${ }^{11,19}$ The decision to change and adopt a new intervention, such as a certain mobilization practice, is reported to be a complex process. ${ }^{20,21}$ Health professionals have to make trade-offs between risks, benefits, costs, and preferences. Engagement in, or avoidance of, a particular intervention is considered to be influenced by "predisposing factors" (eg, past experiences, knowledge, values, interests, and beliefs), "enabling factors" (skills, capacity, resources, availability of services), and "reinforcing factors" (opinions and behavior of others). ${ }^{21}$ In other words, professionals seem more likely to adopt an intervention if it is consistent with their own and their organizations' existing values, needs, and past experiences, and if it is easy to understand and use. ${ }^{20}$

In view of the research activity in this field (ongoing clinical trials), exploring the opinion of stroke care professionals on the topic may help identify barriers or facilitators to clinical uptake once trials are complete. Few studies have investigated professional opinion about early mobilization after stroke. A Scottish survey of 99 nurses, physicians, and physiotherapists highlighted the lack of agreement between stroke care professionals concerning what constitutes early mobilization and who should initiate it. While the majority of nurses $(62 \%)$ and physicians (67\%) had the conception that early mobilization commences within either 12 or 24 hours of stroke onset, most physiotherapists $(76 \%)$ were of the opinion that early mobilization refers to a time point after the first 24 hours. $^{22}$ In the authors' previous paper, it was further reported that up to $24 \%$ of professionals surveyed were firmly of the opinion that mobilization out of bed within 24 hours after stroke was harmful, with more professionals concerned about mobilizing patients with hemorrhagic stroke than ischemic stroke. ${ }^{23}$ In this paper, unique data are presented from the same multidisciplinary group of stroke professionals about when, in their view, first mobilization should take place. Also reported are professionals' views about how early mobilization may affect patients' final outcome, what level of evidence is currently supporting practice, and what level of evidence professionals would need to be convinced of benefit. In this study, "mobilization" was defined as intensive out of bed activity. Wherever the term "early" or "very early" was used, this was specified as within the first 24 hours of stroke onset.

It was hypothesized that:

1. There would be no general agreement about the optimal timing of first mobilization, particularly following hemorrhagic stroke.

2. Most professionals would not think that patients' final physical, cognitive, or mood outcome depends on being mobilized early after stroke onset.

3. Most professionals need evidence from a large randomized controlled trial (RCT), or a systematic review to be convinced of benefit.

\section{Methods}

\section{Study setting and population}

All health care professionals with current or recent experience working with stroke patients were eligible for inclusion. Participants were recruited during the combined Stroke Society of Australasia (SSA) and 4th Smart Strokes Australasian Nursing and Allied Health Conference in Sydney, Australia. Two interviewers, unknown to those to whom they spoke, randomly approached people wearing a congress badge outside the conference rooms, primarily during breaks. Once those people were identified as eligible, they were invited to participate. Agreement to participate indicated consent and the study was approved by the Austin Health Human Research and Ethics Committee. Professionals were given a laminated version of the questionnaire to look at while the interview was performed. Answers were recorded into preprogrammed handheld computers, the PalmOne ${ }^{\mathrm{TM}}$ Zire $^{\mathrm{TM}} 21$ PDA (Palm, Inc, Sunnyvale, CA) with Pendragon ${ }^{\circledR}$ Forms 4.0 (Pendragon Software Corp, Buffalo Grove, IL) software. The questionnaire took approximately 5 minutes to complete.

\section{Survey method}

The nine-item questionnaire developed for this study sought professionals' opinion on the practice of early mobilization after stroke and has been described in more detail elsewhere. ${ }^{23}$ The items related to this analysis follow.

\section{Timing of mobilization}

Professionals who agreed or were undetermined (neither agreed nor disagreed) with the statement that mobilization 
within 24 hours was harmful - that is, were of the opinion that mobilization should occur later than 24 hours post stroke - answered the question: "When do you think it would be appropriate to commence intensive out of bed activity?" For this question they were asked to nominate a time (ie, $>24$ hours but $<48$ hours, $>48$ hours but $<72$ hours, $>3$ days but $<7$ days, 7-14 days) for patients with hemorrhagic or ischemic stroke to start mobilization.

\section{Evidence supporting current practice}

Those who disagreed that early mobilization was harmful were asked to nominate what evidence supported their current views of early mobilization (ie, their own personal experience of benefit, the opinion of experts they trust, clinical studies showing benefit, a positive small RCT, a positive systematic review, a positive large $\mathrm{RCT}$ ).

\section{Evidence needed to be convinced of benefit}

All professionals were also asked to nominate the level of evidence required to be convinced of benefit and change practice.

\section{Contribution of early mobilization to outcome}

Professionals had to rate their level of agreement with three statements that stated that final (1) motor outcome, (2) cognitive outcome, and (3) risk of depression were heavily dependent on patients being mobilized out of bed very early after their stroke.

\section{Definitions}

"Most health professionals" was defined as more than $50 \%$ of participants. "General agreement" was considered to be when $80 \%$ of participants selected the same response.

\section{Data analysis}

This paper reports responses from six of the questionnaire's nine items. Three participants nominated more than one time interval when they thought it would be appropriate to commence intensive out of bed activity. In these cases the latest time frame given was used. Data were summarized and proportions of participants were calculated. Simple descriptives were used to explore the stated hypotheses. Data were analyzed using SPSS (v 17.0; IBM, Armonk, NY).

\section{Results}

In total, 202 professionals were interviewed, representing $38 \%$ of all conference attendees. Among all professionals approached, five did not take part in the survey. Two of these declined without giving an explanation, one was not able to complete because of language difficulties, and two found that their current or recent work experience did not meet entry criteria. Sixty-five percent $(n=132)$ of participating professionals were female, $50 \%(\mathrm{n}=101)$ were $<40$ years old and $64 \%(n=129)$ had $<10$ years of experience working with people with stroke. Forty-six percent $(n=92)$ worked in an acute stroke unit, while $31 \%(n=62)$ worked in rehabilitation. Demographics of the participants are shown in Table 1.

\section{Opinions about when it would be appropriate to start mobilization}

Among the professionals, opinions on when to first mobilize patients varied. Forty percent $(n=80)$ were in favor of mobilizing patients within the first 24 hours of stroke onset, regardless of stroke type (ischemic or hemorrhagic). Another $41 \%(n=83)$ thought that the optimal time point was later than 24 hours after stroke onset, for at least one of the two stroke types. For ischemic stroke, general agreement was almost

Table I Demographic profile of the professionals $(n=202)$

\begin{tabular}{|c|c|c|}
\hline & $\mathbf{n}$ & $\%$ \\
\hline \multicolumn{3}{|l|}{ Age (years) } \\
\hline $20-29$ & 40 & 20 \\
\hline $30-39$ & 61 & 30 \\
\hline $40-49$ & 50 & 25 \\
\hline $50-59$ & 44 & 22 \\
\hline $60-69$ & 6 & 3 \\
\hline$>69$ & 1 & 0 \\
\hline \multicolumn{3}{|l|}{ Gender } \\
\hline Female & 132 & 65 \\
\hline Male & 70 & 35 \\
\hline \multicolumn{3}{|l|}{ Profession } \\
\hline Nursing & 71 & 35 \\
\hline Medicine & 52 & 26 \\
\hline Physiotherapy & 39 & 19 \\
\hline Occupational therapy & 24 & 12 \\
\hline Speech pathology & 9 & 4 \\
\hline Other & 7 & 3 \\
\hline \multicolumn{3}{|l|}{ Experience (years) } \\
\hline$\leq 2$ & 25 & 12 \\
\hline $3-5$ & 51 & 25 \\
\hline $6-10$ & 53 & 26 \\
\hline $11-15$ & 26 & 13 \\
\hline $16-20$ & 14 & 7 \\
\hline $21-30$ & 24 & 12 \\
\hline$>30$ & 9 & 4 \\
\hline \multicolumn{3}{|l|}{ Work } \\
\hline Acute stroke unit & 92 & 46 \\
\hline Rehabilitation & 62 & 31 \\
\hline Acute other unit & 15 & 7 \\
\hline Community care & 13 & 6 \\
\hline Other & 20 & 10 \\
\hline
\end{tabular}


reached that mobilization should begin within 24 hours $(77 \%$, $n=155)$, with only $16 \%(n=33)$ of professionals selecting a time greater than 24 hours but less than 7 days. For hemorrhagic stroke, a higher proportion of professionals responded that the optimal time was after 24 hours $(37 \%, n=76)$. There was no clear agreement in the optimal time point beyond 24 hours. No one thought it would be appropriate to wait for more than 7 days before starting mobilization.

\section{Final outcome related to very early mobilization}

All professionals completed this question. Around three quarters of professionals agreed with the statement that stroke patients' final motor outcome and risk of depression "heavily depends on being mobilized out of bed very early after stroke onset" (Figure 1). Fewer professionals believed there was a link between final cognitive outcome and early mobilization (57\%). Only a small proportion of professionals did not believe that mobilization contributes to motor outcome $(8 \%)$, cognitive outcome $(14 \%)$, or risk of depression $(10 \%)$, and the remainder were unsure of the contribution of mobilization to these poststroke consequences.

\section{Evidence currently supporting the practice of early mobilization}

A total of $80 \%(n=162)$ of professionals agreed that it is beneficial to start intensive out of bed activity within 24 hours, for at least one of the two stroke types. When asked about why they believed that early mobilization is helpful, 35\% $(n=71)$ noted that their opinion was founded on clinical studies showing benefit. Seventeen percent $(n=34)$ based their views on the opinion of experts they trust, $10 \%(n=21)$ on their own personal experience of benefit, and $7 \%(n=15)$

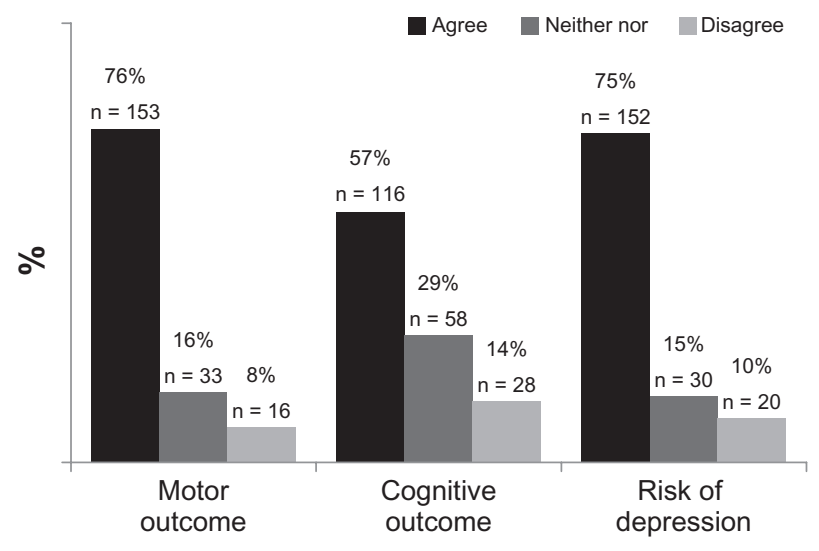

Figure I Professionals' responses to the three statements "In my opinion a patient's final: (I) motor outcome, (2) cognitive outcome, (3) risk of depression, heavily depends on being mobilized out of bed very early after their stroke." on a positive small RCT. Although there are no existing high levels of evidence supporting the efficacy of early mobilization, this option (a positive large RCT or systematic review) was chosen by $17 \%(n=34)$. Opinion about current evidence supporting early mobilization by a professional group is shown in Figure 2.

\section{Evidence needed to be convinced that early mobilization was beneficial}

Regardless of opinion about early mobilization, all professionals were asked what evidence they would need to be convinced that early mobilization was beneficial. Most professionals did not require high-level evidence, with only $19 \%(n=37)$ calling for a large RCT or a systematic review. The level of evidence needed did not vary much among professional groups, with the exception of nurses, who were the professional group with the highest number of respondents $(44 \%, n=31)$ willing to accept personal experience of benefit as acceptable evidence. Figure 3 shows the level of evidence required for each profession.

\section{Discussion}

This study of 202 stroke care professionals found a variety of opinions about when to first mobilize people having suffered a stroke. Although $77 \%$ of professionals agreed that patients with ischemic stroke should be mobilized within 24 hours of stroke onset, $41 \%$ responded that the optimal time for at least one of the stroke types was later than 24 hours but within 7 days. The results of this study indicate that professionals thought people with hemorrhagic stroke should stay longer in bed than those with ischemic stroke. Considering the lack of evidence and clearly defined guidelines regarding early mobilization, this study generated some interesting findings.

First, even though some authors claim that most stroke specialists consider mobilization within 24 hours "too abrupt," 11 there is no evidence of harms, ${ }^{4,24}$ nor clear benefits, of early mobilization. ${ }^{25}$ Even for ischemic stroke, this study did not find general agreement about the timing of mobilization after stroke. This was not surprising given the absence of direct evidence supporting early mobilization. In this study, no professionals agreed that first mobilization should be delayed until after the first week of stroke; however, a small proportion was still happy to delay mobilization for 3-7 days. Professionals who prefer bed rest in the initial stage of stroke are possibly motivated by experimental studies, reporting decreased cerebral blood flow as a potential negative effect of early mobilization. ${ }^{19}$ The potential benefit of early mobilization most commonly espoused is that it may 


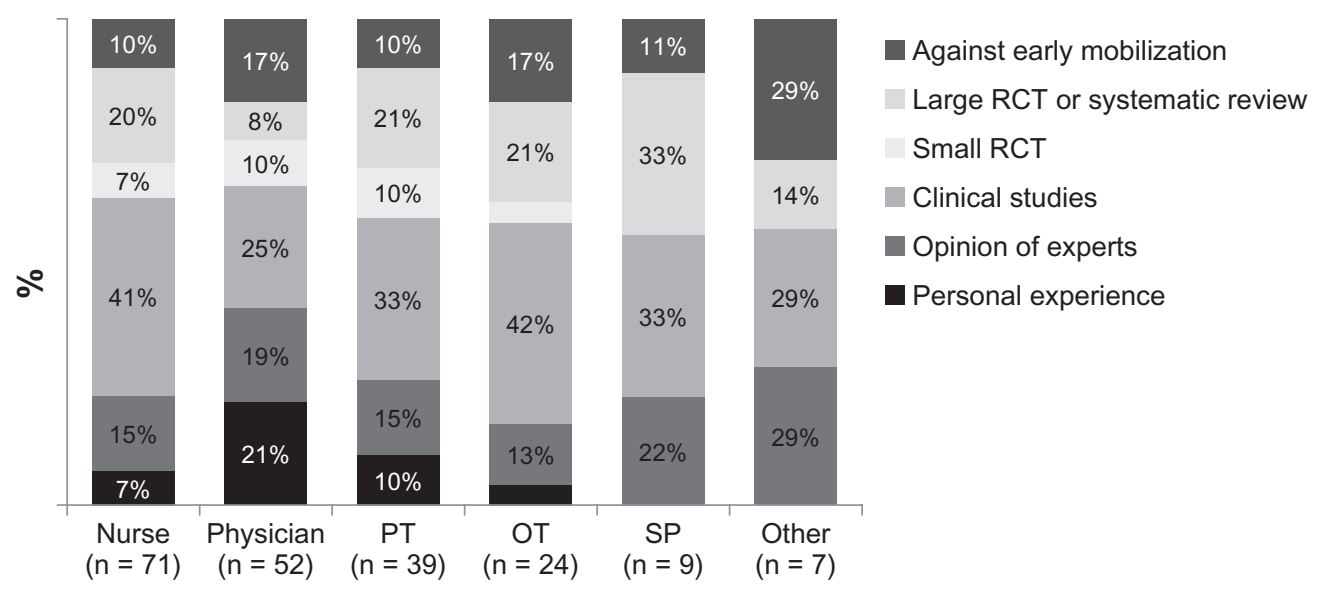

Figure $\mathbf{2}$ The level of evidence currently supporting the practice of early mobilization.

Note: The proportion of health professionals who did not support the practice of early mobilization after stroke (and who did not complete this question) is shown in dark grey Abbreviations: PT, physiotherapist; OT, occupational therapist; SP, speech pathologist; RCT, randomized controlled trial.

reduce immobility-related complications..$^{3,5-8}$ Given that an estimated $82 \%-95 \%$ of acute stroke patients experience secondary complications, of which a substantial proportion are considered to be as a result of immobility, ${ }^{6,724,25}$ interventions that may reduce immobility-related complications would be welcome. Increasingly, early mobilization is being monitored as part of quality assessment, ${ }^{26}$ and ongoing trials should shed light on the relationship between early mobilization and complications. In contrast, the harms of bed rest as a treatment choice for many conditions are well described. ${ }^{5}$

Regardless of the professionals' opinions on when to initiate mobilization, most professionals thought that a stroke patient's final motor outcome, cognition function, and risk of depression heavily depend on being mobilized out of bed very early. This was a surprising finding considering the lack of a solid evidence base and the authors' expectation that professionals would hold varying views on the optimal timing of first mobilization. It was found that professionals were just as likely to expect early mobilization to reduce risk of depression as to improve motor outcome. Although there is some evidence that physical activity may influence motor function, cognition, and mood in other populations, the evidence supporting the effect of early mobilization on these outcomes in people with stroke is very limited. ${ }^{10}$

In spite of the limited evidence base, professionals still have to make decisions about interventions, based on whatever information is available. This pragmatic necessity is likely reflected in the data presented here, which shows that a large proportion of professionals in favor of early mobilization founded their views on lower levels of evidence. More difficult to explain is that $17 \%$ based their opinion on a positive large RCT or a systematic review, when none exist; ${ }^{25}$ it is possible that not all professionals interviewed were confident in using the terms "randomized

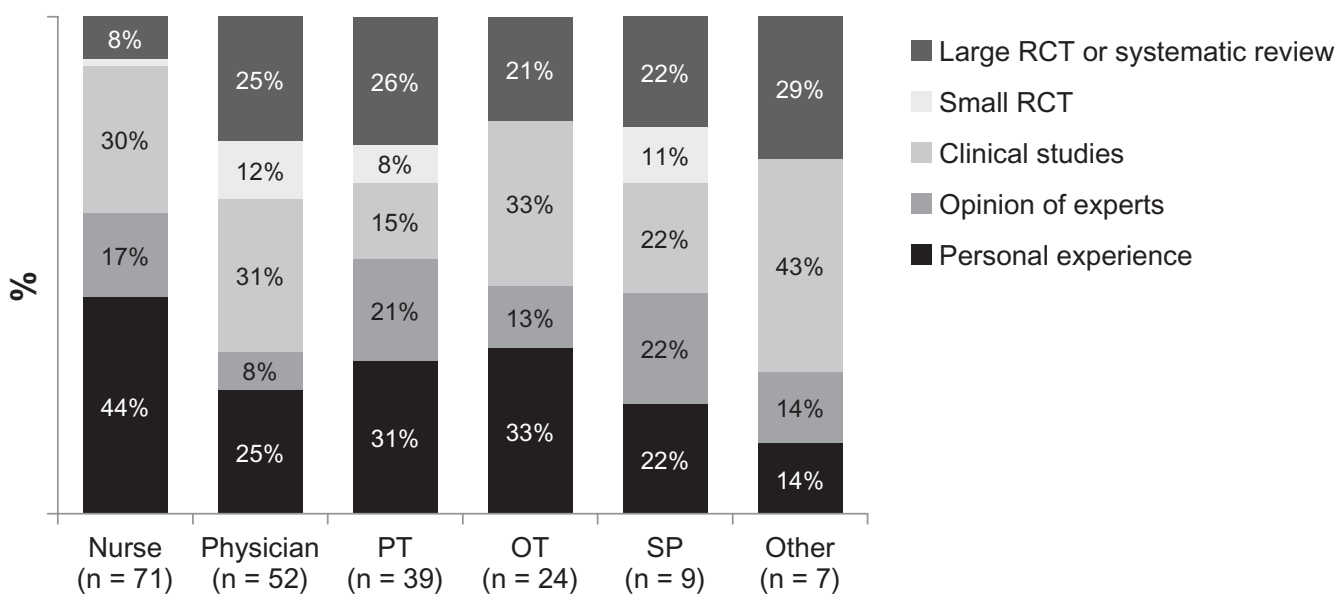

Figure 3 The level of evidence professionals would need to be convinced of benefit.

Abbreviations: PT, physiotherapist; OT, occupational therapist; SP, speech pathologist; RCT, randomized controlled trial. 
controlled trial" and "systematic review." According to an Australian survey from 2001, ${ }^{27} 13 \%$ of general practitioners stated that they did not understand the term "randomized controlled trial." The same practitioners' familiarity with "systematic reviews" was reported to be even poorer, with as many as $35 \%$ having no knowledge about the term. ${ }^{27}$ Lack of confidence and skills to interpret, synthesize, and apply research findings have further been found to limit professionals' use of best available evidence. ${ }^{27-29}$ Another major barrier to evidence uptake and application reported by $67 \%$ of 488 physiotherapists ${ }^{30}$ and $92 \%$ of 649 occupational therapists $^{29}$ is the absence of protected work time to search and appraise the research literature. This may explain the authors' finding in the present study that a large proportion of professionals would be convinced of the benefits of mobilization based on lower levels of evidence. The authors' results are moreover consistent with other studies indicating that personal experience and the opinion of experts or colleagues are the sources of information most frequently relied on in clinical decision-making. ${ }^{27,29}$

It is acknowledged that surveys of this kind may be affected by error sources such as respondent misunderstanding or guessing, and it is also difficult to know how well professionals' answers reflect their actual current practice. ${ }^{31}$ It should also be noted that people attending a professional development conference of this kind may represent those who are most interested in learning, and therefore tend to stay more connected with recent evidence compared with others. The timing of an interview in relation to the conference program, which included presentations on both early mobilization and initial bed rest, may also have affected the answers. Face-to-face interviews are another factor that might have influenced professionals to respond in a certain way, although the interviewers were completely unknown to the attendants at the conference. Further, the questionnaire was deliberately kept very short and simple, with no scope to further explore responses, since it was aimed to capture the opinion of a relatively large group of people attending a busy conference. Despite these limitations, this study identified some important potential barriers and facilitators to the practice of early mobilization, which is emerging as an important topic in stroke care and would be worth exploring in more detail in the future.

\section{Conclusion}

Clinical guidelines around the world recommend early mobilization after stroke but provide few specific practice directives. This study found professional opinion varies and that mobilization within 24 hours is acceptable to some professionals but could be delayed up to 7 days poststroke by others. Solid evidence of safety, benefits, and cost-effectiveness would help the development of specific practice guidelines; however, the results of this study suggest that high-quality trials will only have some influence on professionals' opinion about the practice of very early mobilization.

\section{Acknowledgments}

The authors would like to thank Toby Cumming, Janice Collier, Jan Chamberlain, Fiona Ellery, Leonid Churilov, and coworkers at Florey Neuroscience Institutes. They also wish to acknowledge the organizers of the integrated Society of Australasia (SSA) and 4th Smart Strokes Australasian Nursing and Allied Health Conference for allowing them to conduct this study, along with all the professionals who took part in the survey.

\section{Disclosure}

The authors report no conflicts of interest for this paper.

\section{References}

1. Govan L, Weir CJ, Langhorne P. Organised inpatient (stroke unit) care for stroke. Stroke. 2008;39:2402-2403.

2. Stroke Unit Trialists' Collaboration. How do stroke units improve patient outcomes? A collaborative systematic review of the randomized trials. Stroke. 1997;28:(11)2139-2144.

3. Indredavik B, Bakke F, Slordahl SA, Rokseth R, Haheim LL. Treatment in a combined acute and rehabilitation stroke unit: which aspects are most important? Stroke. 1999;30(5):917-923.

4. Bernhardt J, Dewey H, Thrift A, Collier J, Donnan G. A very early rehabilitation trial for stroke (AVERT): phase II safety and feasibility. Stroke. 2008;39(2):390-396.

5. Allen C, Glasziou P, Del Mar C. Bed rest: a potentially harmful treatment needing more careful evaluation. Lancet. 1999;354(9186): $1229-1233$.

6. Langhorne P, Stott DJ, Robertson L, et al. Medical complications after stroke: a multicenter study. Stroke. 2000;31(6):1223-1229.

7. Johnston KC, Li JY, Lyden PD, et al. Medical and neurological complications of ischemic stroke: experience from the RANTTAS trial. RANTTAS Investigators. Stroke. 1998;29(2):447-453.

8. Topp R, Ditmyer M, King K, Doherty K, Hornyak J 3rd. The effect of bed rest and potential of prehabilitation on patients in the intensive care unit. AACN Clin Issues. 2002;13(2):263-276.

9. Langhorne P, Stott D, Knight A, Bernhardt J, Barer D, Watkins C. Very early rehabilitation or intensive telemetry after stroke: a pilot randomised trial. Cerebrovasc Dis. 2010;9(4):352-360.

10. Cumming TB, Collier J, Thrift AG, Bernhardt J. The effect of very early mobilisation after stroke on psychological well-being. $J$ Rehabil Med. 2008;40(8):609-614.

11. Diserens K, Michel P, Bogousslavsky J. Early mobilisation after stroke: Review of the literature. Cerebrovasc Dis. 2006;22(2-3):183-190.

12. Bernhardt J, Dewey H, Collier J, et al. A Very Early Rehabilitation Trial (AVERT). Int J Stroke. 2006;1(3):169-171.

13. European Stroke Organisation (ESO) Executive Committee. Guidelines for management of ischaemic stroke and transient ischaemic attack 2008. Cerebrovasc Dis. 2008;25(5):457-507. 
14. Adams HP Jr, Adams RJ, Brott T, et al. Guidelines for the early management of patients with ischemic stroke: A scientific statement from the Stroke Council of the American Stroke Association. Stroke. 2003;34(4):1056-1083.

15. Adams HP Jr, del Zoppo G, Alberts MJ, et al. Guidelines for the early management of adults with ischemic stroke: a guideline from the American Heart Association/American Stroke Association Stroke Council, Clinical Cardiology Council, Cardiovascular Radiology and Intervention Council, and the Atherosclerotic Peripheral Vascular Disease and Quality of Care Outcomes in Research Interdisciplinary Working Groups: the American Academy of Neurology affirms the value of this guideline as an educational tool for neurologists. Stroke. 2007;38(5):1655-1711.

16. Asplund K. National guidelines for stroke care: support for priority setting. In: Welfare TSNBoHa, editor. The Swedish National Board of Health and Welfare; 2005. Available from: http://www.socialstyrelsen. se/Lists/Artikelkatalog/Attachments/8934/2007-102-10_200710210. pdf. Accessed 20 September 2011.

17. Hill K; Acute Stroke Management Expert Working Group. Australian Clinical Guidelines for Acute Stroke Management 2007. Int J Stroke. 2008;3(2):120-129.

18. Bernhardt J, Indredavik B, Dewey H, et al. Mobilisation 'in bed' is not mobilisation. Cerebrovasc Dis. 2007;24(1):157-158; author reply 159.

19. Bernhardt J. Very early mobilization following acute stroke: Controversies, the unknowns, and a way forward. Ann Indian Acad Neurol. 2008;11(5):88-98.

20. Dobbins M, Ciliska D, Cockerill R, Barnsley J, DiCenso A. A framework for the dissemination and utilization of research for health-care policy and practice. Online J Knowl Synth Nurs. 2002;E9(1):149-160.

21. Grol R, Wensing M. What drives change? Barriers to and incentives for achieving evidence-based practice. Med J Aust. 2004;180(6 Suppl): S57-S60.
22. Arias M, Smith LN. Early mobilization of acute stroke patients. J Clin Nurs. 2007;16(2):282-288.

23. Skarin M, Bernhardt J, Sjoholm A, Nilsson M, Linden T. 'Better wear out sheets than shoes': a survey of 202 stroke professionals' early mobilisation practices and concerns. Int J Stroke. 2011;6(1):10-15.

24. Sorbello D, Dewey HM, Churilov L, et al. Very early mobilisation and complications in the first 3 months after stroke: further results from phase II of A Very Early Rehabilitation Trial (AVERT). Cerebrovasc Dis. 2009;28(4):378-383.

25. Bernhardt J, Thuy MN, Collier JM, Legg LA. Very early versus delayed mobilization after stroke. Stroke. June, 42000.

26. Svendsen ML, Ehlers LH, Andersen G, Johnsen SP. Quality of care and length of hospital stay among patients with stroke. Med Care. 2009;47(5):575-582.

27. Young JM, Ward JE. Evidence-based medicine in general practice: beliefs and barriers among Australian GPs. J Eval Clin Pract. 2001;7(2):201-210.

28. De Vito C, Nobile CG, Furnari G, et al. Physicians' knowledge, attitudes and professional use of RCTs and meta-analyses: a cross-sectional survey. Eur J Public Health. 2009;19(3):297-302.

29. Bennett S, Tooth L, McKenna K, et al. Perceptions of evidence-based practice: A survey of Australian occupational therapists. Aust Occup Ther J. 2003;50:13-22.

30. Jette DU, Bacon K, Batty C, et al. Evidence-based practice: beliefs, attitudes, knowledge, and behaviors of physical therapists. Phys Ther. Sep 2003;83(9):786-805.

31. Burns AC, Bush RF. Marketing Research. 5th ed. Upper Saddle River, NJ: Pearson Education; 2006. 
Appendix Nine-item questionnaire

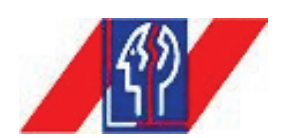

\section{Professional Opinions About Early Mobilization After Stroke: A 9 Item Questionnaire.}

To help us describe the population studied, we need some information about your:

- Age group: $20-29 ; 30-39 ; 40-49 ; 50-59 ; 60-69 ;>69$ years

- Gender

- Profession

- Experience with stroke patients (years): $<2 ; 3-5 ; 6-10 ; 11-15 ; 16-20 ; 21-30 ;>30$

- Current work environment: acute stroke unit, acute other unit; rehabilitation; community care

The 9 item questionnaire below seek your views about the harms or benefits of very early and intensive physical rehabilitation for people who have recently suffered a stroke.

Q1. In my opinion acute stroke patients need a lot of bed rest to recover, and should not start physical activity too soon

\begin{tabular}{|c|c|c|c|c|}
$\begin{array}{c}\text { Strongly } \\
\text { disagree }\end{array}$ & Disagree & $\begin{array}{c}\text { Neither } \\
\text { agree nor } \\
\text { disagree }\end{array}$ & Agree & $\begin{array}{c}\text { Strongly } \\
\text { agree }\end{array}$ \\
1 & 2 & 3 & 4 & 5 \\
\hline
\end{tabular}

Q2. In my opinion it is harmful to start early and intensive out of bed activity of patients within 24 hours of having an:

\begin{tabular}{|c|c|c|c|c|c|}
\hline a. Ischemic stroke & $\begin{array}{c}\text { Strongly } \\
\text { disagree }\end{array}$ & Disagree & $\begin{array}{c}\text { Neither } \\
\text { agree nor } \\
\text { disagree }\end{array}$ & Agree & $\begin{array}{c}\text { Strongly } \\
\text { agree }\end{array}$ \\
\cline { 1 - 5 } b. Hemorrhagic stroke & $\begin{array}{c}\text { Strongly } \\
\text { disagree }\end{array}$ & Disagree & $\begin{array}{c}\text { Neither } \\
\text { agree nor } \\
\text { disagree }\end{array}$ & Agree & $\begin{array}{c}\text { Strongly } \\
\text { agree }\end{array}$ \\
\cline { 1 - 3 } & 1 & 2 & 3 & 4 & 5 \\
\hline
\end{tabular}

Q3. If you answered "Neither agree nor disagree - strongly agree" that early physical activity may be harmful in Question 2, when do you think it would be appropriate to commence intensive out of bed activity?

Q3a Ischemic stroke (multiple choices possible)

- $>24$ hours but less than 48 hours after stroke onset

- $>48$ hours but less than 72 hours after stroke onset

- $>3$ days but within 7 days

- 7-14 days

- on reaching rehabilitation

- completely dependent on the patients' physical ability

- completely dependent on the patients' wishes

- when cardiovascularly stable
Q3b Hemorrhagic stroke (multiple choices possible)

- >24 hours but less than 48 hours after stroke onset

- $>48$ hours but less than 72 hours after stroke onset

- $>3$ days but within 7 days

- 7-14 days

- on reaching rehabilitation

- completely dependent on the patients' physical ability

- completely dependent on the patients' wishes

- when cardiovascularly stable 


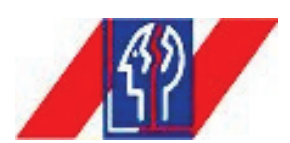

Q4. What evidence would you need to convince you that commencing intensive out of bed activity within 24 hours of stroke onset was beneficial to patients?: (Can choose one or more)

- My own personal experience of benefit

- The opinion of experts I trust

- Clinical studies showing benefit
- A positive small randomized controlled trial

- A positive systematic review

- A positive large randomized controlled trial

Q5. I believe it is helpful to start early and intensive out of bed activity of people within $\mathbf{2 4}$ hours of having an:

\begin{tabular}{|c|c|c|c|c|c|}
\hline a. Ischemic stroke & \multirow{2}{*}{$\begin{array}{c}\text { Strongly } \\
\text { disagree } \\
1\end{array}$} & \multirow{2}{*}{$\begin{array}{c}\text { Disagree } \\
2\end{array}$} & \multirow{2}{*}{$\begin{array}{c}\text { Neither } \\
\text { agree nor } \\
\text { disagree } \\
3\end{array}$} & \multirow{2}{*}{$\begin{array}{c}\text { Agree } \\
\\
4\end{array}$} & \multirow{2}{*}{$\begin{array}{c}\text { Strongly } \\
\text { agree } \\
5\end{array}$} \\
\hline & & & & & \\
\hline \multirow[t]{2}{*}{ b. Hemorrhagic stroke } & $\begin{array}{l}\text { Strongly } \\
\text { disagree }\end{array}$ & Disagree & $\begin{array}{l}\text { Neither } \\
\text { agree nor }\end{array}$ & Agree & $\begin{array}{l}\text { Strongly } \\
\text { agree }\end{array}$ \\
\hline & 1 & 2 & 3 & 4 & 5 \\
\hline
\end{tabular}

Q6. I believe that commencing intensive out of bed activity within 24 hours of stroke onset is helpful to patients because: (Can choose one or more)

- My own personal experience of benefit

- The opinion of experts I trust

- Clinical studies showing benefit
- A positive small randomized controlled trial

- A positive systematic review

- A positive large randomized controlled trial

NOTE: if you answered "agree, strongly agree” to Q2 (harmful) you may skip Q6.

Q7-9. In my opinion a patients' final (Q7) motor, (Q8) cognition and (Q9) risk of depression heavily depends on being mobilized out of bed very early after their stroke.

\begin{tabular}{|c|c|c|c|c|c|}
\hline Q7. Motor outcome & $\begin{array}{c}\text { Strongly } \\
\text { disagree } \\
1\end{array}$ & $\begin{array}{c}\text { Disagree } \\
2\end{array}$ & $\begin{array}{c}\text { Neither } \\
\text { agree nor } \\
\text { disagree } \\
3\end{array}$ & $\begin{array}{c}\text { Agree } \\
4\end{array}$ & $\begin{array}{c}\text { Strongly } \\
\text { agree } \\
5\end{array}$ \\
\hline \multirow[t]{2}{*}{ Q8. Cognitive outcome } & \multirow{2}{*}{$\begin{array}{c}\text { Strongly } \\
\text { disagree } \\
1\end{array}$} & \multirow{2}{*}{$\begin{array}{c}\text { Disagree } \\
2\end{array}$} & \multirow{2}{*}{$\begin{array}{c}\text { Neither } \\
\text { agree nor } \\
\text { disagree }\end{array}$} & \multirow{2}{*}{$\begin{array}{c}\text { Agree } \\
\\
4\end{array}$} & \multirow{2}{*}{$\begin{array}{c}\begin{array}{c}\text { Strongly } \\
\text { agree }\end{array} \\
5\end{array}$} \\
\hline & & & & & \\
\hline \multirow[t]{2}{*}{ Q9. Risk of depression } & $\begin{array}{l}\text { Strongly } \\
\text { disagree }\end{array}$ & Disagree & $\begin{array}{l}\text { Neither } \\
\text { agree nor }\end{array}$ & Agree & $\begin{array}{c}\text { Strongly } \\
\text { agree }\end{array}$ \\
\hline & 1 & 2 & 3 & 4 & 5 \\
\hline
\end{tabular}




\section{Publish your work in this journal}

The Journal of Multidisciplinary Healthcare is an international, peerreviewed open-access journal that aims to represent and publish research in healthcare areas delivered by practitioners of different disciplines. This includes studies and reviews conducted by multidisciplinary teams as well as research which evaluates the results or conduct of such teams or

healthcare processes in general. The journal covers a wide range of areas and welcomes submission from practitioners at all levels, from all over the world. The manuscript management system is completely online and includes a very quick and fair peer-review system. Visit http://www.dovepress.com/testimonials.php to read real quotes from published authors.

Submit your manuscript here: http://www.dovepress.com/journal-of-multidisciplinary-healthcare-journal 